\title{
ALS-based estimation of plot volume and site index in a eucalyptus plantation with a nonlinear mixed-effect model that accounts for the clone effect
}

\author{
Petteri Packalén • Lauri Mehtätalo • Matti Maltamo
}

Received: 3 September 2010 / Accepted: 28 March 2011 /Published online: 24 August 2011

(C) INRA and Springer Science+Business Media B.V. 2011

\begin{abstract}
- Introduction Most airborne laser scanning (ALS) studies have been carried out in semi-natural forests, but some research has also been carried out in plantations. Results indicate that methods similar to those which are used in semi-natural forest are also usable in plantation forestry. The study was conducted in a pulpwood plantation growing Eucalyptus urograndis in Bahia State, Brazil.

- Objectives The aims of this study are to investigate (1) how accurately the plot volume may be estimated by ALS data in eucalyptus plantations and (2) how to estimate the site index directly by combining ALS data and stand age. The plot volume and site index were estimated by means of nonlinear mixed-effect modeling in order to take into account the stand-within-clone hierarchy of the data.

- Results The obtained accuracies are quite good if compared to those obtained in semi-natural forests. The root-mean-square error was $8.2 \%$ for plot volume and $2.7 \%$ for site index when the clone effect was used in prediction.

- Conclusions Precision forestry applied in plantations differs in many ways from the forestry practiced in a semi-natural environment. ALS-based forest inventory methods have a great deal of potential in pulpwood plantations when the unique features of plantation forestry are taken into account.
\end{abstract}

\footnotetext{
Handling Editor: Reinhart Ceulemans

P. Packalén $(\bowtie) \cdot$ L. Mehtätalo $\cdot$ M. Maltamo

Faculty of Science and Forestry, University of Eastern Finland, P.O. Box 111, 80101 Joensuu, Finland

e-mail: petteri.packalen@uef.fi

L. Mehtätalo

e-mail: lauri.mehtatalo@uef.fi

M. Maltamo

e-mail: matti.maltamo@uef.fi
}

Keywords Airborne laser scanning · Nonlinear mixedeffect modeling $\cdot$ Volume $\cdot$ Site index $\cdot$ Eucalyptus plantation $\cdot$ Area-based method $\cdot$ Lidar. Forest inventory

\section{Introduction}

Plantation forestry differs in many ways from the forestry practiced in semi-natural environments. There are several kinds of forest plantations. The aim may be to provide wildlife habitat, biological diversity, and other services in addition to wood production; in that case, multi-species forest plantations are favored (FAO 2002). However, nearly all the tropical plantations are grown in monoculture, with one species being planted over a large area. The primary reason for this is that silviculture is simpler (Evans 1992).

Although most airborne laser scanning (ALS) studies have been done in semi-natural forests, some research has also been carried out in plantations (e.g., McCombs et al. 2003; Wack et al. 2003; Roberts et al. 2005; Donoghue et al. 2007; Rombouts et al. 2008; Hopkinson et al. 2008; Tesfamichael 2009; Zonete et al. 2010). The focus in these studies has been the accuracy of ALS-based stand attribute estimates including leaf area and growth. Results indicate that methods similar to those used in semi-natural forests also seem to be appropriate for plantation forestry. So far, most studies have dealt with conifer plantations, an exception being the articles by Wack et al. (2003); Zonete et al. (2010) and the PhD thesis by Tesfamichael (2009, cf. journal publications) in which eucalyptus was considered. Both area-based method (Næsset 2002) and individual tree detection (Hyyppä and Inkinen 1999) have been used in studies concerning plantations.

The type of plantation considered here is a mono-species eucalyptus plantation which is targeted for pulpwood 
production only. In eucalyptus plantations, trees are planted in rows using a fixed stand density. However, the stand density does not necessarily remain the same over the rotation since some damage may occur. There is no natural regeneration, thus trees within a stand are genuinely of the same age and single storied.

Eucalyptus is the most important short fiber source for pulp and paper production in Brazil due to its rapid growth and excellent pulp properties (Shatalov et al. 1999; Siverio et al. 2007). The Eucalyptus hybrid considered in this study, for instance, may grow over $60 \mathrm{~m}^{3} /$ ha/year; thus, the yield is extremely high compared to most natural or semi-natural forests (Siverio et al. 2007). A great deal of effort has been devoted to improving the quality, growth, and yield of eucalyptus species by means of genetic selection. The yield potential of a stand can be seen as an interaction of physiographic factors, such as soil and climate, species and seed origin (in this study, a clone), and management actions such as soil preparation, fertilization, etc. (Clutter et al. 1983; Eerikäinen et al. 2002). In eucalyptus plantations, the aim is to select the most productive and suitable clone to a particular stand. Typically, all trees in a stand belong to the same clone. In practice, the growth and yield potential is quantified by site index (SI), which is usually based on the development of dominant height over the rotation period.

Forest inventory in eucalyptus plantations is normally carried out solely by field measurements. These surveys cover a portion of the population, and sampling design varies. Permanent sample plots are often used since information about growth is important. By using permanent sample plots, it is possible to construct growth models and to monitor, for example, the growth rate of particular clone. Pre-harvest inventories are also carried out in eucalyptus plantations. In such cases, temporary sample plots are used. It is typical that a certain length of row or rows constitutes a sample plot, or that fixed number of trees defines a plot. Sample plots are placed either systematically or randomly, depending on the purpose of the inventory. Determining plot locations accurately is not a normal routine in eucalyptus plantations.

Plantation forestry also occupies a special situation regarding remote sensing-based forest assessment. Although the stand level information about age and tree species is also often available for semi-natural forests, this information is especially accurate in even-age plantations where trees are of the same age and, in certain cases, of a known clone. This makes it more feasible to combine existing stand register data and remote sensing data and to carry out estimation in a wall-to-wall manner. Accurate age at tree level also enables the estimation of attributes which are normally not feasibly estimated by remote sensing.

The aims of this study are to investigate (1) how accurately the plot volume (V) may be estimated by ALS data in eucalyptus plantation and (2) how to estimate SI directly by combining ALS data and age taken from the stand register. In order to efficiently utilize all available information, the estimation was carried out with a nonlinear mixed-effect model that accounts for the clone effect.

\section{Materials}

\subsection{Study area and field data}

The study was performed at a pulpwood plantation growing eucalyptus in Bahia State, Brazil $\left(16^{\circ} 05^{\prime} \mathrm{S} 39^{\circ} 24^{\prime} \mathrm{W}\right)$. The plantation is owned by Veracel, and the pulp mill itself is sited within the test area. The cultivated eucalyptus species is Eucalyptus urograndis, which is a hybrid between Eucalyptus grandis and Eucalyptus urophylla. This eucalyptus hybrid is highly productive and is one of the main species currently used for pulp production in Brazil (Siverio et al. 2007).

A network of 195 circular sample plots with a radius of $13 \mathrm{~m}$ was established and measured in August-September 2008. Sample plots were placed in 55 forest stands with three or four plots per stand. Satellite positioning was used to determine the position of each plot center using a realtime differential correction signal from the OmniSTAR satellite (http://www.omnistar.com). The trees are grown in rows, and the tree spacing is fixed, giving a density of 833 stems per hectare. However, damages may reduce the stem density. All trees were recorded in the field for diameter at breast height $(d)$ and quality, and every seventh tree on each plot was measured for height $(h)$. Näslund's (1937) $h-d$ curve was fitted by stands and used to predict heights for trees without height measurement. Stem volumes were calculated as a function of $d$ and $h$ using a clone- and age class-specific model constructed in-house in Veracel.

Plot volume (V) was calculated by aggregating from tree to plot level, and dominant height (HD) was calculated as the mean height of the 100 thickest trees at breast height per hectare. Stand age $(T)$ was taken from the plantation database in which this parameter was registered at intervals of 1 month. There were 28 different clones in the 55 stands from which the field data were collected. All trees in a stand belonged to the same clone. The site index (SI) was predicted using the following form of the ChapmanRichards equation (Clutter et al. 1983):

$\mathrm{SI}=\mathrm{HD}\left(\frac{1-e^{-\beta_{1} t_{\text {reference }}}}{1-e^{-\beta_{1} t_{\text {current }}}}\right)^{\beta_{2}}$

where $t_{\text {reference }}$ is the reference age of 7 years, HD is the current dominant height, $t_{\text {current }}$ is the current age, and $\beta_{1}$ $(0.3341)$ and $\beta_{2}(1.1442)$ are known model parameters in 
Veracel. Information on the essential stand characteristics is presented in Table 1.

\subsection{Airborne laser scanning data}

ALS data were collected on August 16, 2008 using an Optech ALTM 3100 laser scanning system. The test site was measured from an altitude of approximately 1,200 m above ground level using a field of view of $30^{\circ}$. Pulse repetition frequency was set to 50,000 pulses per second, which resulted a nominal sampling density of about 1.5 measurements per square meter. The footprint was about $35 \mathrm{~cm}$ at ground level.

A digital terrain model (DTM) was generated from the ALS data. First, laser points were classified as ground and non-ground points using the method reported by Axelsson (2000). Then, a raster DTM with a 1-m pixel size was interpolated using ground points and an inverse distance weighting algorithm (Lloyd and Atkinson 2002). Finally, the raster DTM was subtracted from the ellipsoidal heights of laser points in order to scale the ALS data to the above ground level (AGL).

\section{Methods}

\subsection{Explanatory variables}

The laser scanner used captures a maximum of four range measurements for each submitted pulse. These echo categories are "first of many," "last of many," "only," and "intermediate." After preliminary tests, it was decided that only the echo categories "first of many" and "only" would be used in this study, since the exclusion of "last of many" and "intermediate" echoes did not significantly decrease the accuracy of the SI and Vestimates. This set contains all of the first - or surface - echoes since an "only" echo may also be considered as a first echo.

Numerous height and density metrics were calculated from the combined set of "first of many" and "only" echoes. The principle of the area-based method was used here (Næsset 2002). The first step was to calculate height distributions for each sample plot using the heights of the

Table 1 Mean, standard deviation (SD), minimum and maximum values of site index (SI), age and volume (V) at the plot level $(n=195)$

\begin{tabular}{lccc}
\hline & SI $\left(\mathrm{m} t_{\text {reference }}\right)$ & Age (years) & $\mathrm{V}\left(\mathrm{m}^{3} \mathrm{ha}^{-1}\right)$ \\
\hline Mean & 34.3 & 7.3 & 376.1 \\
SD & 1.76 & 2.6 & 132.8 \\
Min & 29.2 & 2.5 & 117.7 \\
Max & 39.2 & 11.9 & 655.7 \\
\hline
\end{tabular}

AGL data. All the laser hits were considered, also ground hits. Height quantiles for $5 \%, 10 \%, 20 \%, \ldots, 80 \%, 90 \%$, $95 \%$ (h5, .., h95) were computed, and the corresponding densities $(\mathrm{p} 5, \ldots, \mathrm{p} 95)$ were calculated for the respective quantiles. Height quantiles were calculated by summing the heights at AGL. For instance, the metric h50 is the height at which $50 \%$ of the cumulative height has accumulated and p50 is the number of laser hits below h50 divided by all the laser hits on the plot. In addition, the mean (hmean) and standard deviation (hstd) of heights at AGL were calculated by plots. These metrics form a set of candidate explanatory variables used for modeling SI and V.

\subsection{Modeling of site index and plot volume}

The same form of the Chapman-Richards equation which is used to predict the SI in this plantation was used as the starting point in the modeling of SI (see Eq. 1). However, instead of modeling the HD separately and inserting the resulting predictions into Eq. 1, the SI was modeled directly. This was done by replacing the HD of Eq. 1 with a linear dominant height model that uses ALS-based explanatory variables and fitting the equation as a nonlinear model into the modeling data. Site index results from multiplying the dominant height with a function of the current stand age (Eq. 1). Because the function is nonlinear in stand age, fitting a model for dominant height and using it in Eq. 1 might result in biased prediction of site index. Our formulation ensures that the model is unbiased for site index. We also incorporated nested random effects into the model to account for the effects of the hierarchical data (sample plot within stand within clone). To begin with, however, the form of the HD model was chosen by using linear regression. At this stage, both manual insertion and deletion of explanatory variables and a stepwise selection based on the Akaike information criterion were used.

Preliminary analyses for the model of $\mathrm{V}$ showed a linear relationship between $\ln (\mathrm{V})$ and the predictors, which is why a nonlinear model of the exponential form was used to model the total volume. This led to a model that has the observed linear relationship and is unbiased for V. This model was also fitted as a mixed-effect model to account for data hierarchy.

The nonlinear mixed-effect models were fitted by using the nlme routine (Pinheiro and Bates 2000) in the $R$ environment ( $R$ Development Core Team 2009) by the method of restricted maximum likelihood and the algorithm of Lindstrom and Bates (1990).

\subsection{Accuracy assessment}

Accuracy assessment was carried out by leave-one-out cross validation (LOOCV) in order to avoid too positive 
results. In LOOCV model, parameters were repeatedly estimated by ignoring the observation for which the prediction is done. Therefore, the exact parameter estimates reported in Table 2 were not used in LOOCV. Accuracy assessment was carried out at three different levels: for the fixed part of the mixed-effect model, by using the predicted clone effect, and by using the predicted stand and clone effects. The accuracy of estimates was evaluated in terms root-mean-square error (RMSE) and bias at the plot level:

$\mathrm{RMSE}=\sqrt{\frac{\sum_{i=1}^{n}\left(y_{i}-\widehat{y}_{i}\right)^{2}}{n}}$

$\mathrm{BIAS}=\sqrt{\frac{\sum_{i=1}^{n}\left(y_{i}-\widehat{y}_{i}\right)}{n}}$

where $n$ is the number of plots, $y_{i}$ is the observed value for plot $i$, and $\widehat{y}_{i}$ is the predicted value for plot $i$. Moreover, the relative RMSEs and biases were calculated by dividing the absolute values (Eqs. 2 and 3) by the true mean of the variable in question.

\section{Results}

\subsection{Nonlinear mixed-effect models}

The model for the SI is as follows:

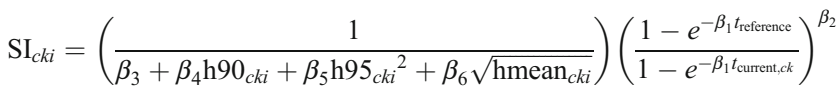

$$
\begin{aligned}
& +b_{c}+b_{c k}+\varepsilon_{c k i}
\end{aligned}
$$

where $\mathrm{SI}_{c k i}$ is the SI for clone $c$, stand $k$, and plot $i ; b_{c}$ is a random clone effect; $b_{c k}$ is a random stand effect (stands are nested within clones); and $\varepsilon_{c k i}$ is the residual for clone $c$, stand $k$, and plot $i . \beta_{1}$ and $\beta_{2}$ are the known parameters of the SI model (the same as in Eq. 1). The random effects and residuals are assumed to be uncorrelated and normally distributed with mean zero and constant variance.

The model for the plot volume is as follows:

$\mathrm{V}_{c k i}=e^{\left(\beta_{7}+\beta_{8} \log (\mathrm{h} 10)+\beta_{9} \log (\mathrm{h} 50)+\beta_{10} \sqrt{\mathrm{p} 90}+b_{c}+b_{c k}\right)}+\varepsilon_{c k i}$

where $\mathrm{V}_{c k i}$ is $\mathrm{V}$ for clone $c$, stand $k$, and plot $I ; b_{c}$ is a random clone effect; $b_{c k}$ is a random stand effect (stands are nested within clones); and $\varepsilon_{c k i}$ is the residual for clone $c$, stand $k$, and plot $i$. The random effects and residuals are assumed to be normally distributed with mean zero and constant variance. Preliminary analyses showed increasing residual variance with respect to the prediction, so the residual was assumed to be normally distributed with mean zero and variance $\operatorname{var}\left(\varepsilon_{c k i}\right)=\sigma^{2} \mathrm{~h} 50^{2 \delta}$, where $\sigma$ and $\delta$ are the parameters of the power-type variance function. The parameter estimates for both models are listed in Table 2.

\subsection{Accuracies}

The RMSE and bias of the LOOCV estimates of SI and V are presented in Table 3. Level denotes the level of grouping used for obtaining the predictions. Level "fixed" means that only the fixed part of the model (Eqs. 4 or 5) is used, level "clone" means that the predicted clone effect is used in the prediction, and "stand" means that the predicted random effect for the stand within clone is also used in the prediction.

The accuracy of estimation of SI was $1.11 \mathrm{~m}$ at the reference age of 7 years when only the fixed part of the model was used in the prediction. The inclusion of random effects improved the accuracy notably but not quite as much as in the case of V. The SI estimates were virtually unbiased at all levels of grouping. In relative terms, the accuracy of SI was very good; however, this is mainly a consequence of the range of SI (see also Fig. 1).

The estimates of $\mathrm{V}$ were already rather accurate without random effects (Table 3); however, the inclusion of random clone effects improved the accuracy from $11.86 \%$ to $8.77 \%$, and the further inclusion of random stand effects decreased
Table 2 Parameter estimates for the fixed independent variables and estimated variances for random effects at the clone, forest stand, and plot level
Equation 4

\begin{tabular}{lrllll}
\hline Coefficient & Estimate & SE & Coefficient & Estimate & \multicolumn{1}{l}{ SE } \\
$\beta_{3}$ & 0.0977596 & 0.0028945 & $\beta_{7}$ & 11.415382 & 2.298940 \\
$\beta_{4}$ & -0.0034367 & 0.0001932 & $\beta_{8}$ & 0.142945 & 0.077417 \\
$\beta_{5}$ & 0.0000432 & 0.0000031 & $\beta_{9}$ & 1.460686 & 0.095138 \\
$\beta_{6}$ & -0.0008237 & 0.0003894 & $\beta_{10}$ & -1.133237 & 0.236214 \\
Random parameters & $0.478231^{2}$ & & Random parameters \\
$\operatorname{Var}\left(b_{c}\right)$ & $0.726614^{2}$ & & $\operatorname{Var}\left(b_{c}\right)$ & $0.064235^{2}$ \\
$\operatorname{Var}\left(b_{c k}\right)$ & $0.659612^{2}$ & & $\operatorname{Var}\left(b_{c k}\right)$ & $0.065542^{2}$ \\
$\operatorname{Var}\left(\varepsilon_{c k i}\right)$ & & $\operatorname{Var}\left(\varepsilon_{c k i}\right)$ & $0.015319^{2} \mathrm{~h} 50^{4.236}$ \\
\hline
\end{tabular}


Table 3 The RMSE and bias of the estimates of SI and V at different levels of grouping using LOOCV

\begin{tabular}{|c|c|c|c|c|}
\hline \multirow[b]{2}{*}{ Level } & \multicolumn{2}{|l|}{ SI } & \multicolumn{2}{|l|}{$\mathrm{V}$} \\
\hline & RMSE & Bias & RMSE & Bias \\
\hline Fixed & $1.11 \mathrm{~m}, 3.22 \%$ & $0.14 \mathrm{~m}, 0.41 \%$ & $44.61 \mathrm{~m}^{3}, 11.86 \%$ & $8.24 \mathrm{~m}^{3}, 2.19 \%$ \\
\hline Clone & $0.96 \mathrm{~m}, 2.81 \%$ & $0.03 \mathrm{~m}, 0.10 \%$ & $33.00 \mathrm{~m}^{3}, 8.77 \%$ & $1.46 \mathrm{~m}^{3}, 0.39 \%$ \\
\hline Stand & $0.78 \mathrm{~m}, 2.28 \%$ & $0.01 \mathrm{~m}, 0.03 \%$ & $26.32 \mathrm{~m}^{3}, 7.00 \%$ & $-0.28 \mathrm{~m}^{3},-0.07 \%$ \\
\hline
\end{tabular}

the RMSE to $7.00 \%$. There was some bias in the estimates of $\mathrm{V}$ when only the fixed part of the model was used. In absolute terms, the accuracy of $\mathrm{V}$ was between 26 and $45 \mathrm{~m}^{3} \mathrm{ha}^{-1}$.

Figure 1 depicts the plots of observed versus predicted SI and Vat the "clone" level. In relative terms, the variation around the line of perfect fit is greater in the case of SI than in the case of V. In both cases, however, the trend is predicted fairly well. Increasing residual variance with respect to the prediction is apparent in the case of $\mathrm{V}$. With the selected model form, the non-homogeneous variance was satisfactorily modeled by a variance function of the power form.

\section{Discussion}

Precision forestry applied to plantations differs in many ways from the forestry practiced in semi-natural environments. ALS-based forest inventory and assessment has a great deal of potential in pulpwood plantations when the unique features of plantation forestry are taken into account.

In this study, SI was modeled directly in one stage. Another option is a two-stage approach, where the HD is first modeled and then the resulting prediction is used in the known SI curve. The direct modeling approach is justified

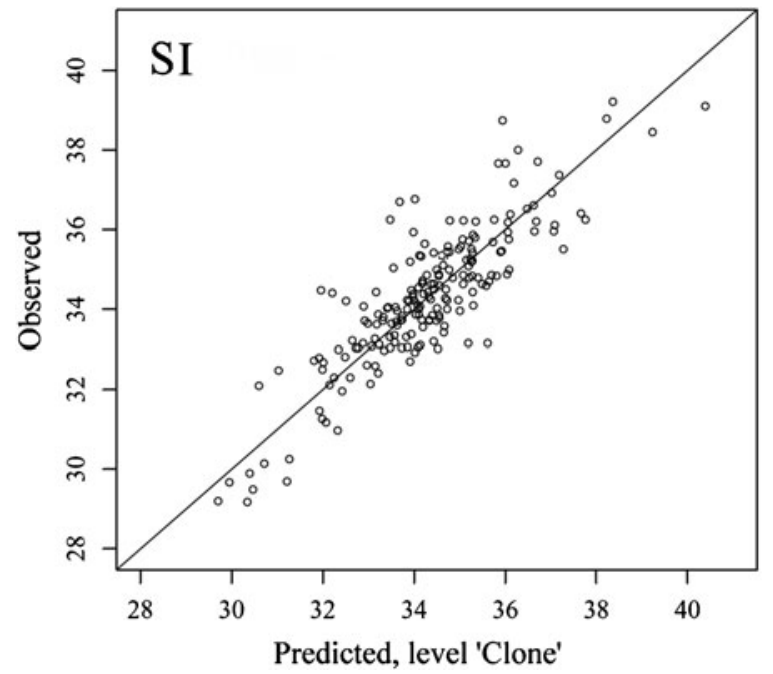

since the only use of the predicted HD is the prediction of SI. In addition, the model was fitted in a nonlinear form, where the SI was treated as an independent variable as such, without transformations. These two methodological choices led to unbiased prediction of SI, which could not have been guaranteed by using the two-stage method and/or a linearized form of the applied HD model. Also, the applied nonlinear model for plot volume led to an unbiased prediction of volume.

Using the clone and stand effects in the prediction improved the accuracy of the prediction considerably. This improvement resulted from using all the plot-specific observations of the response (Vor SI) for the stand or clone under consideration in the prediction. For clones that do not have measurements available, this level of accuracy is not possible because the prediction can be done only at the "fixed" level. For clones with measurements from different stands, the prediction can be done at the "clone" level. Prediction at the "stand" level can be done only if sample plot measurements from that particular stand are available. The practical use of the model arises from the possibility of using the clone effect in the prediction for stands with no measured sample plots. In those cases, the prediction could be close to the reported accuracy at the clone level.

The accuracy of plot-level volume prediction in this study was better than what has been found in earlier studies

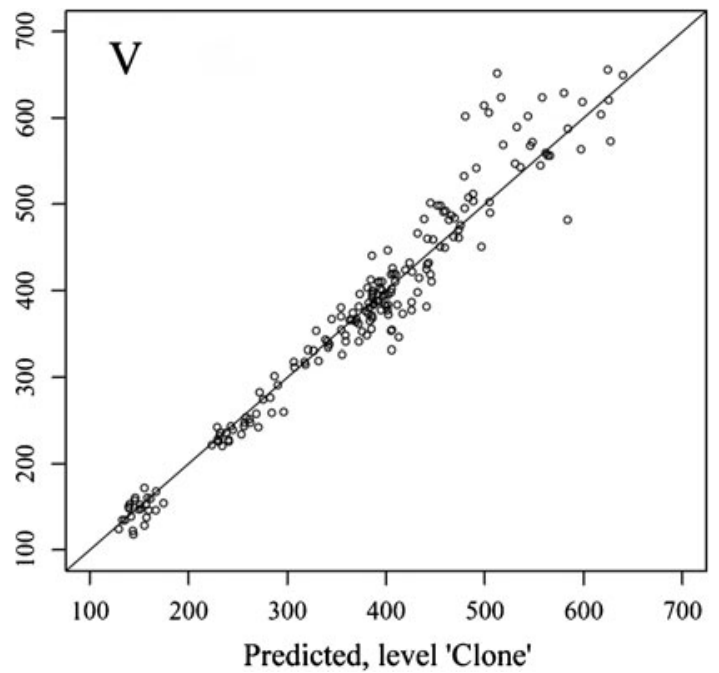

Fig. 1 Observed versus predicted SI ( $\left.\mathrm{m} t_{\text {reference }}\right)$ and $\mathrm{V}\left(\mathrm{m}^{3} \mathrm{ha}^{-1}\right)$ at the "clone" level. The solid line indicates a perfect fit 
concerning boreal forests. For example, in the review by Næsset et al. (2004), the plot-level accuracy varied between $15 \%$ and $20 \%$. This is, of course, also dependent on plot size. The results reported here, including clone effects, are far more accurate than what Maltamo et al. (2006) obtained on large plots $\left(900 \mathrm{~m}^{2}\right)$ in boreal forests, with relative RMSE values of $8.82 \%$ and $12.0 \%$, respectively. This indicates that plantation forests can be characterized more accurately by ALS than semi-natural forests.

Breidenbach et al. (2008) applied linear mixed-effect models with a random intercept on the stand level on the three study sites in the USA and Germany. Comparable area-based method was used as here. The RMSE of the volume by study sites was $16.7 \%, 24.3 \%$, and $32.1 \%$. Compared with the fixed-effects models fitted with generalized least squares, the use of mixed-effect modeling with random stand effects improved the RMSE only from $2 \%$ to $4 \%$. Here, the inclusion of random clone and stand effects improved the accuracy more. One reason for this may be the homogeneity of eucalyptus stands. Therefore, in eucalyptus plantation, a larger proportion of unexplained variance is caused by between-stand (and clone) variation than in semi-natural forests, and this variance may be accounted for by random clone and stand effects.

The RMSE of $\mathrm{V}$ at the "clone" level decreased from $8.77 \%$ to $6.73 \%$ when the accuracy was assessed by LOOCV at the stand level using an average of three to four plots per stand. This indicates that more accurate results can be obtained at the stand level. However, three to four plots represent only a rather small area when compared to the average stand size of the plantation, which is over 20 ha. This indicates that the true values used in evaluation include sampling errors and that, at the whole stand level, the accuracy could be even better. The comparison of accuracies of traditional field survey and ALS-based inventory at the stand level was not possible here because of the lack of suitable field data. This kind of comparison would be desirable but remain a task of future study. An advantage of ALS-based forest inventory is $100 \%$ areal coverage, whereas in field surveys, some sampling error always exists. This makes a comparison quite laborious and expensive to implement.

In eucalyptus plantations, stands are even-aged and the exact planting date is known. Since ALS data cover 100\% of an inventory area, it is possible to predict SI based on HD and age, or SI may be predicted directly as done here. Figure 2 depicts SI predicted on a grid using a cell size of $15 \mathrm{~m}$. The prediction was carried out by Eq. 4 at the "clone" level. Only one stand is presented in Fig. 2. There is an apparent trend in SI, with decreasing productivity from south to north. The benefit and added value that remote sensing bring is the within stand variation of SI, since it provides new possibilities to carry out precision

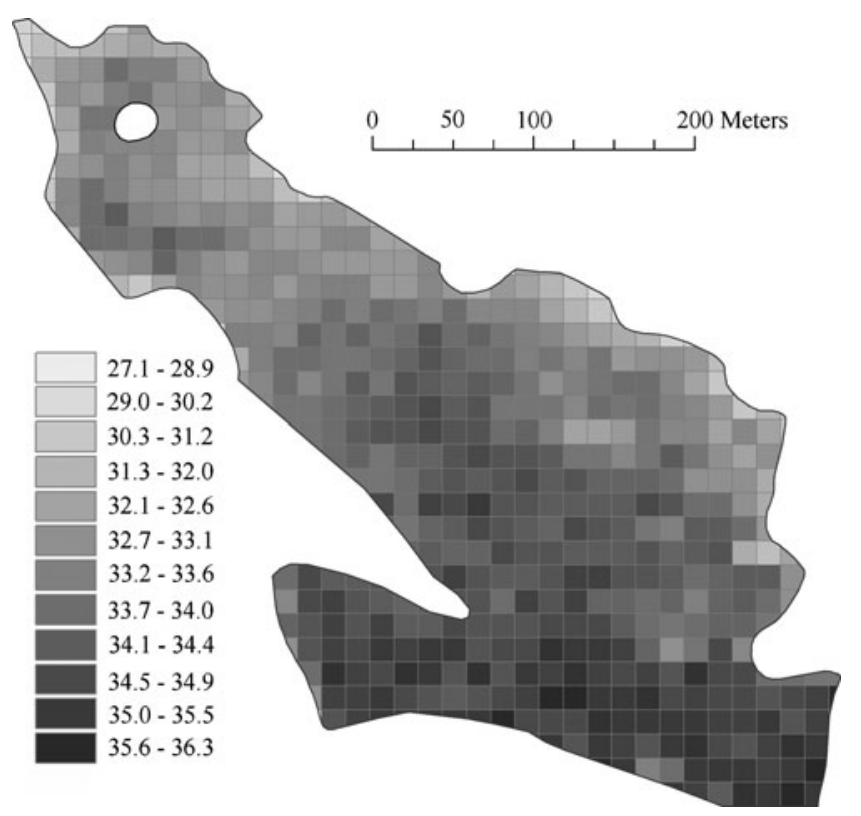

Fig. 2 Predicted SI ( $\mathrm{m} t_{\text {reference }}$ ) in one stand using a cell size of $15 \mathrm{~m}$. The clone effect was taken into account in the prediction

forestry. For instance, it may be used for guiding or monitoring fertilization by pinpointing accurately more and less productive areas within a stand.

The normal use of SI is to assess the growth potential of a stand when a certain tree species is grown. The model presented in this paper includes a joint model of SI for all the clones of the modeling dataset. In addition, it is possible to predict the clone effect for new clones of the same species. Thus, instead of providing a site index model for only one clone, it can be seen as an SI model family that can be used for different clones of Eucalyptus urograndis.

Permanent sample plots are used in eucalyptus plantation to provide data to construct growth models and to monitor the growth rate. Often these models are clone specific. In addition, the same data may be used to construct clonespecific volume models. Therefore, permanent sample plots cannot be replaced by remote sensing since field measurements are needed for other purposes too. One alternative would be to use permanent sample plots as the field sample plots of the ALS-based forest inventory. For pre-harvest inventory purposes, ALS-based wall-to-wall prediction of growing stock might suit well. In that case, the essential question is timing: how often should inventory be carried out? In any case, plot positions must be determined accurately in ALS-based forest inventory, which is not the current practice.

An alternative approach to estimating growing stock by ALS data is to carry out individual tree detection. The advantage of such an approach is that less sample plots are needed, but on the other hand, individual tree detection requires that tree positions are determined on the field and 
that ALS data is denser (a higher number of pulses per square meter). Individual tree detection provides many possibilities because it inherently provides tree-level data, but in pulpwood plantations tree-level information is not of primary interest. The situation differs considerably in sawnwood plantations. For example, in pine plantations, the primary interest may be in diameter distribution or even only in the most largest and valuable sawn-wood trees. In such cases, ALS should provide information on tree diameter, which is challenging both on individual tree (Maltamo et al. 2009) and area-based approaches (e.g., Packalén and Maltamo 2008).

The point cloud collected by ALS is dependent on the scanning configuration, e.g., the pulse repetition frequency or flying altitude, and the response also varies among different sensors (Næsset 2009). Therefore, such kind of area-based models as presented here must be made case-by-case by plantations, but from the operational point of view, this is not a major restriction. If several sensors or different scanning configurations are used, the sensor or scanning configuration effect may be taken into account as a random effect in a similar manner as were the clone and stand considered here. However, this probably decreases the accuracy.

The clone level explained a considerable amount of the between-stand variation for both models, and including the clone effect in the prediction considerably improves the accuracy. This observation leads to suggesting the placing of sample plots over the whole inventory area so that some measurements are available for all clones. The prediction could then be carried on a grid for the whole plantation at the clone level. Final inventory results may be obtained by aggregation to stand level, or cell level results may be used as such.

\section{References}

Axelsson P (2000) DEM generation from laser scanner data using adaptive TIN models. Intl Archives Photogram Remote Sens 33:110-117

Breidenbach J, Kublin E, McGaughey R, Andersen H-E, Reutebuch S (2008) Mixed-effects models for estimating stand volume by means of small footprint airborne laser scanner data. Photogram J Finland 21:4-15

Clutter JL, Fortson JC, Pienaar LV, Brister GH, Bailey RL (1983) Timber management: a quantitative approach. Wiley, New York, $334 \mathrm{p}$

Donoghue DNM, Watt PJ, Cox NJ, Wilson J (2007) Remote sensing of species mixtures in conifer plantations using LiDAR height and intensity data. Remote Sens Environ 110:509-522

Eerikäinen K, Mabvurira D, Nshubemuki L, Saramäki J (2002) A calibrateable site index model for Pinus kesiya plantations in southeastern Africa. Can J For Res 32:1916-1928

Evans J (1992) Plantation forestry in the tropics: tree planting for industrial, social, environmental, and agroforestry purpose, 2nd edn. Oxford University Press, USA, 403 p
FAO (2002) Forest plantation productivity. Report based on the work of W.J. Libby and C. Palmberg-Lerche. In: Forest plantation thematic papers, working paper 3. Forest Resources Development Service, Forest Resources Division. FAO, Rome

Hopkinson C, Chasmer L, Hall RJ (2008) The uncertainty in conifer plantation growth prediction from multi-temporal lidar datasets. Remote Sens Environ 112:1168-1180

Hyyppä J, Inkinen M (1999) Detecting and estimating attributes for single trees using laser scanner. Photogram $\mathrm{J}$ Finland $16: 27-42$

Lindstrom MJ, Bates DM (1990) Nonlinear mixed effects models for repeated measures data. Biometrics 46:673-687

Lloyd CD, Atkinson PM (2002) Deriving DSMs from LiDAR data with kriging. Int J Remote Sens 23:2519-2524

Maltamo M, Eerikäinen K, Packalén P, Hyyppä J (2006) Estimation of stem volume using laser scanning-based canopy height metrics. Forestry 79:217-229

Maltamo M, Peuhkurinen J, Malinen J, Vauhkonen J, Packalén P, Tokola T (2009) Predicting tree attributes and quality characteristics of Scots pine using airborne laser scanning data. Silva Fennica 43:507-521

McCombs JW, Roberts SD, Evans DL (2003) Influence of fusing lidar and multispectral imagery on remotely sensed estimates of stand density and mean tree height in a managed loblolly pine plantation. For Sci 49:457-466

Næsset E (2002) Predicting forest stand characteristics with airborne scanning laser using a practical two-stage procedure and field data. Remote Sens Environ 80:88-99

Næsset E (2009) Effects of different sensors, flying altitudes, and pulse repetition frequencies on forest canopy metrics and biophysical stand properties derived from small-footprint airborne laser data. Remote Sens Environ 113:148-159

Næsset E, Gobakken T, Holmgren J, Hyyppä H, Hyyppä J, Maltamo M, Nilsson M, Olsson H, Persson Å, Söderman U (2004) Laser scanning of forest resources: the Scandinavian experience. Scand J For Res 19:482-499

Näslund M (1937) Skogsförsöksanstaltens gallringsförsök i tallskog. Meddelanden från Statens Skogsförsöksanstalt 29, 169 p. (In Swedish)

Packalén P, Maltamo M (2008) Estimation of species-specific diameter distributions using airborne laser scanning and aerial photographs. Can J For Res 38:1750-1760

Pinheiro JC, Bates DM (2000) Mixed-effects models in S and S-PLUS. Springer, New York, $528 \mathrm{p}$

R Development Core Team (2009) R: a language and environment for statistical computing. R Foundation for Statistical Computing, Vienna. http://www.R-project.org

Roberts SD, Dean TJ, Evans DL, McCombs JW, Harrington RL, Glass PA (2005) Estimating individual tree leaf area in loblolly pine plantations using LiDAR-derived measurements of height and crown dimensions. For Ecol Manag 213:54-70

Rombouts J, Ferguson IS and Leech JW (2008) Variability of LiDAR volume prediction models for productivity assessment of radiata pine plantations in South Australia. In: Hill R, Rosette J, Suárez J (eds) Proceedings of SilviLaser 2008, 8th international conference on LiDAR applications in forest assessment and inventory, Edinburgh, UK, pp. 39-49

Shatalov AA, Evtuguin DV, Neto CP (1999) (2-O- $\alpha$-D-Galactopyranosyl-4-O-methyl- $\alpha$-D-glucurono)-D-xylan from Eucalyptus globulus Labill. Carbohydr Res 320:93-99

Siverio FO, Barbosa LCA, Maltha CRA, Silvestre AJD, Pilo-Veloso D, Gomide JL (2007) Characterization of lipophilic wood extractives from clones of Eucalyptus urograndis cultivated in Brazil. BioResources 2:157-168

Tesfamichael SG (2009) Assessment of structural attributes of evenaged Eucalyptus grandis forest plantations using small-footprint 
discrete return lidar data. PhD thesis, University of KwaZuluNatal, South Africa, 194 p

Wack R, Schardt M, Barrucho L, Lohr U and Oliveira T (2003) Forest inventory for eucalyptus plantations based on airborne laser scanner data. In: Proceedings of the International Society for Photogrammetry and Remote Sensing Symposium, International Archives of the Photogrammetry, Remote Sensing and Spatial Information Sciences, 34, Commission III/W13, 40-46, The Netherlands

Zonete M, Rodriguez L, Packalén P (2010) Estimação de parâmetros biométricos de plantios clonais de eucalipto no sul da Bahia: uma aplicação da tecnologia laser aerotransportada. Scientia Forestalis 86:225-235 (In Portuguese) 